\title{
Perthes-Like Disease Masquerading Non-Classical MPS
}

Journal of Inborn Errors

of Metabolism \& Screening

2020, Volume 8: e20200003

DOI: 10.1590/2326-4594-JIEMS-2020-0003

\author{
Carolina F.M. Souza ${ }^{1} \oplus$, Ana Cecília Siqueira ${ }^{2}$ Natália S. Antunes ${ }^{3}$, \\ Dafne D.G. Horovitz ${ }^{4}$, Juan Politei ${ }^{5}$, Charles M. Lourenço ${ }^{6} \odot$, Maria Juliana \\ Rodovalho Doriqui ${ }^{7}$, Débora Lima Souza ${ }^{8}$, Marcial Francis Galera9, \\ Leonardo Cury Abrahão ${ }^{10}$, Marcos Almeida Matos ${ }^{11} \odot$, Pedro Henrique \\ Barros Mendes ${ }^{4,12}$ and Tatiana S.P.C Magalhães ${ }^{13}$
}

\begin{abstract}
Mucopolysaccharidoses (MPS) are inborn errors of metabolism caused by deficient lysosomal enzymes, leading to organomegaly, hip osteonecrosis, coarse facial features, bone deformities, joint stiffness, cardiac and pulmonary symptoms (MPS VI) or hypermobility (MPS IVA). Some patients may present with non-classical forms of the disease in which osteoarticular abnormalities are the initial symptoms of non-classical forms. As orthopedists and surgeons are the specialists most frequently consulted before the diagnosis, it is critical that MPS may be considered as a differential diagnosis for patients with bone dysplasia. Experts in Latin America reviewed medical records focusing on disease onset, first symptoms and the follow-up clinical and surgical outcomes of non-classical MPS $\mathrm{VI}$ and IVA patients. All patients displayed orthopedic issues, which worsened over time, followed by cardiac and ophthalmological abnormalities. Our findings enlighten the necessity of including non-classical MPS as possible diagnosis for patients who report osteoarticular abnormalities in absence of inflammation.
\end{abstract}

\section{Keywords:}

slowly progressive MPS, Morquio A syndrome, Maroteaux-Lamy syndrome, osteoarticular abnormalities, hip dysplasia.

\section{Introduction}

Mucopolysaccharidoses (MPS) are a group of inborn errors of metabolism that arise from deficient lysosomal enzymes involved in degradation of glycosaminoglycans (GAG). These molecules are important components of extracellular matrix, joint fluid and connective tissue. When GAG are accumulated, it compromises the proper function of several organs, leading to MPS clinical manifestations [1].

MPS VI (Maroteaux-Lamy) and IVA (Morquio A) are transmitted by autosomal recessive inheritance, and they are marked by deficiency of arylsulfatase $\mathrm{B}(\mathrm{N}$-acetylgalactosamine 4-sulfatase) and $\mathrm{N}$-acetyl-galactosamine-6-sulfate sulfatase, respectively, leading to accumulation primarily of dermatan sulphate (MPS VI) and keratan sulphate (MPS IVA) in tissues and organs $[2,3]$.

Clinical manifestations of MPS VI include joint stiffness, short stature, organomegaly, hip osteonecrosis, coarse facial

\footnotetext{
${ }^{1}$ Hospital de Clínicas de Porto Alegre, Porto Alegre, RS, Brazil. ${ }^{2}$ Instituto de Medicina Integral Professor Fernando Figueira, Caruaru, PE, Brazil. ${ }^{3}$ Ambulatório de Genética e do Centro de Referência em Erros Inatos do Metabolismo, Recife, PE, Brazil.

${ }^{4}$ Instituto Fernandes Figueira, Departamento de Genética Médica, Flamengo, RJ, Brazil.

${ }^{5}$ Fundación para el Estudio de Enfermedades Neurometabólicas, Laboratorio de Neuroquímica Dr. N. A. Chamoles, Buenos Aires, Argentina.

${ }^{6}$ Faculdade de Medicina, Centro Universitário Estácio de Ribeirão Preto, Ribeirão Preto, SP, Brazil.

${ }^{7}$ Serviço de Referência em Triagem Neonatal do Maranhão, São Luís, MA, Brazil.

${ }^{8}$ Unidade Básica de Saúde Iraci Lula Mendes, Espinosa, MG, Brazil.

' Universidade Federal do Mato Grosso, Departamento de Pediatria, Cuiabá, MT, Brazil

${ }^{10}$ Serviço de Ortopedia Infantil do Hospital Ortopédico BH, MG, Brazil.

${ }^{11}$ Universidade do Estado da Bahia, Escola Bahiana de Medicina e Saúde Pública, Salvador, BA, Brazil.

${ }^{12}$ Instituto Nacional de Traumatologia e Ortopedia, Rio de Janeiro, RJ, Brazil. ${ }^{13}$ Biomarin Pharmaceutical Ltda., São Paulo, SP, Brazil.
}

Received March 14, 2020, and in revised form Revised May 7, 2020. Accepted for publication June 12, 2020

\section{Corresponding Author:}

Marcos Almeida Matos, Bahiana School of Medicine and Public Health, Universidade do Estado da Bahia, BA, Brazil.

Email: marcos.almeida@hotmail.com 
features and bone deformities, besides cardiac respiratory and ophthalmologic concerns. Similar signs are found in MPS IVA but with joint hypermobility [4]. Skeletal abnormalities are an early and prominent feature of most MPS disorders, with the degree of skeletal involvement varying between and within MPS subtypes, with classical types of MPS IV A and VI including severe bone involvement. Most patients with the classical phenotype exhibit a constellation of radiographic abnormalities known as dysostosis multiplex, consisting of abnormally shaped vertebrae and ribs, enlarged skull, spatulate ribs, hypoplastic epiphyses, thickened diaphysis and bullet-shaped metacarpals $[2,4]$. For both MPS disorders, affected patients are cognitively normal [5].

The severity and disease progression among individuals with MPS VI and IVA vary due to the causative mutations that lead to different degrees of residual enzyme activity and a possible contribution of environmental and metabolic factors. Therefore, a broad variability in clinical presentation has been described as classical and non-classical phenotypes. The nonclassical forms of MPS lead to milder systemic manifestations in contrast with the classical forms $[5,6]$. Thus, patients with non-classical phenotypes generally have clinical manifestation onset at a later age and the symptoms may be limited to reduced height, less pronounced cardiac and pulmonary symptoms, facial features and skeletal deformities in MPS VI [7]; and to minor skeletal abnormalities, hip pain, and moderate short stature in MPS IVA $[8,9]$.

Due to clinical heterogeneity of MPS disorders, diagnosis is frequently delayed in patients with non-classical phenotype [5]. For instance, a case series showed that patients with non-classical MPS VI remained misdiagnosed for over 30 years regardless of the presence of the cardinal symptoms of this disease [10]. Similarly, it was reported that a 51-year-old man who was believed to have Perthes disease for 38 years despite displaying coarse facial features, corneal clouding, pectus carinatum and a mild thoracolumbar kyphosis [11].

\section{Aims}

It has been reported that patients with non-classical MPS VI or IVA commonly display osteoarticular problems, joint pain and hip dysplasia as initial symptoms, which trigger their referral to a pediatric orthopedist or rheumatologist $[12,13]$. As these specialists are the target group for the correct detection of nonclassical forms of MPS, they should be prepared to recognize and diagnose MPS or to exclude it [14]. To gauge these specialists' familiarity with non-classical MPS patients in Latin America, the present work reported the clinical history and outcomes of a series of patients with MPS VI and IVA followed in different reference centers for inborn errors of metabolism resembling Perthes disease.

\section{Methods}

A retrospective observational study was performed between March 2018 and March 2019 including non-classical MPS patients identified in five Latin-American sites. Non-classical patients were defined as those presenting attenuated or mild phenotype $[5,7,8,9]$. All procedures were conducted in accordance with the ethical standards of the Helsinki Declaration of 1975, as revised in 2000 . The study was approved by the Institutional Ethic Committee and informed consent was obtained from all patients (or their parents, when legally obliged) prior to inclusion in the study.

Inclusion criteria was none or mild systemic manifestation along with minor orthopedic features, such as short stature and less pronounced abnormalities (pain, gait problems, claw hand, kyphoscoliosis, genu valgum). There were no exclusion criteria or sample size calculation because of the rarity of the condition.

Anthropometric, biochemical, genetic, clinical history and follow-up outcomes data were retrospectively extracted from medical records by medical specialists, who were also asked for complementary data when necessary. MPS diagnoses were confirmed through enzyme activity or genetic analysis. Besides, radiologic exams were provided from the center where the patient has been assisted. Authors assessed all the exams in order to draw a detailed characterization of the radiologic features. Hip/pelvis radiography was especially analyzed by the senior pediatric orthopedists.

Fourteen patients (nine with MPS VI and five with MPS IVA) from reference centers in Brazil and in Argentina were identified and enrolled in the study. Their hip radiographic were evaluated in search of the following findings: acetabular dysplasia (particularly in the superolateral aspect), enlargement and flattening of the femoral head, nucleus fragmentation, irregular physis and metaphysis, coxa valga, migration or subluxation of the head.

Descriptive statistics was used to perform the analysis, using frequencies and percentages to represent categorical data variables. Continuous data variables were summarized by the number of subjects (n), mean, standard deviation, median, minimum, and maximum values. Patients presenting at least three of the radiographic characteristics were considered to have Perthes-like disease.

\section{Results}

Table 1 depicts the demographic data and the biochemical and genetic diagnosis of all patients $(n=14)$. In the MPS VI subpopulation $(n=9 / 14), 66.67 \%$ of the patients were male $(n=6 / 9)$ and $33.3 \%$ female $(n=3 / 9)$. For MPS IVA, $40 \%$ of patients were male $(n=2 / 5)$ and $60 \%$ were female $(n=2 / 5)$. 
Table 1 - Patient demographics, diagnosis and biochemical and mutation analysis

\begin{tabular}{|c|c|c|c|c|c|c|}
\hline Patient & Sex & $\begin{array}{l}\text { MPS } \\
\text { type }\end{array}$ & $\begin{array}{l}\text { Age at diagnosis } \\
\text { (years) }\end{array}$ & $\begin{array}{l}\text { Enzyme } \\
\text { analysis }\end{array}$ & uGAG & Mutation \\
\hline 1 & $\mathrm{~F}$ & $\mathrm{VI}$ & 10 & 13 & 122 & $\begin{array}{l}\text { Compound heterozygosis: c. } 311 \mathrm{~A}>\mathrm{C} \\
\text { (p.Gln104Pro) and c.438G>A (p.Trp146) }\end{array}$ \\
\hline 2 & $\mathrm{~F}$ & $\mathrm{VI}$ & 43 & 97 & 77 & $\begin{array}{l}\text { Compound heterozygosis: c.427delG (p.Val143fs) } \\
\text { and c.275C > T (p.Thr92Met) }\end{array}$ \\
\hline 3 & M & $\mathrm{VI}$ & 31 & 3 & 120 & $\begin{array}{l}\text { Compound heterozygosis: c. } 1143-1 \mathrm{G}>\mathrm{C} \text { and } \\
\text { c. } 277 \mathrm{C}>\mathrm{T} \text { (p.Pro93Ser) in exon } 1\end{array}$ \\
\hline 4 & M & $\mathrm{VI}$ & 29 & 4 & 88 & $\begin{array}{l}\text { Compound heterozygosis: c. } 1143-1 \mathrm{G}>\mathrm{C} \text { in exon } \\
6 \text { and c. } 629 \mathrm{~A}>\mathrm{G} \text { (p.Tyr210Cys) in exon } 3\end{array}$ \\
\hline 5 & M & $\mathrm{VI}$ & 36 & 9 & 68 & $\begin{array}{l}\text { Compound heterozygosis: c. } 1143-1 \mathrm{G}>\mathrm{C} \text { in exon } \\
6 \text { and c. } 629 \mathrm{~A}>\mathrm{G} \text { (p.Tyr210Cys) in exon } 3\end{array}$ \\
\hline 6 & M & $\mathrm{VI}$ & 5 & 10 & 50 & $\begin{array}{l}\text { Compound heterozygosis: c. } 1143-1 \mathrm{G}>\text { and } \\
\text { c. } 1143-8 \mathrm{~T}>\mathrm{GC}\end{array}$ \\
\hline 7 & M & $\mathrm{VI}$ & 9 & 2.1 & $?$ & No pathogenic mutations found \\
\hline 8 & M & $\mathrm{VI}$ & 45 & 12 & 44 & $\begin{array}{l}\text { Compound heterozygosis: c. } 1143-8 \mathrm{~T}>\mathrm{G} \text { and } \\
\text { c.629A }<\mathrm{G} \text { (p.Tyr210Cys) }\end{array}$ \\
\hline 9 & M & $\mathrm{VI}$ & 15 & 9 & 180 & Heterozygosis: 1534_1556del23 (p.5509Leu) \\
\hline 10 & M & IVA & 11 & 3 & $?$ & Homozygotes for p.Asp388Asn \\
\hline 11 & M & IVA & 13 & 4.9 & 55.73 & $?$ \\
\hline 12 & $\mathrm{~F}$ & IVA & 52 & 2.9 & Normal & $\begin{array}{l}\text { Compound heterozygosis: p.Gly301Cys and } \\
\text { p.Ala324fs }\end{array}$ \\
\hline 13 & $\mathrm{~F}$ & IVA & 10 & 1.1 & Normal & $?$ \\
\hline 14 & M & IVA & 10 & 0 & ? & $?$ \\
\hline
\end{tabular}

M: male; F: female; uGAG: urinary glycosaminoglycans (normal range: 72-175 $\mu \mathrm{g} / \mathrm{g} / \mathrm{mg}$ creatinine); ?: not known. Patients 4 and 5 are siblings. Biochemical analysis of arylsulfatase B (normal range: $72-176 \mu \mathrm{g} / \mathrm{h} / \mathrm{mg}$ protein or 116 to $287 \mu \mathrm{g} / \mathrm{h} / \mathrm{mg}$ protein for patient \#2) for MPS type $\mathrm{VI}$ and $\mathrm{N}$-acetylgalactosamine-6-sulfatase (normal range: $>8 \mu \mathrm{mol} / / / 20 \mathrm{~h}$ ) for MPS type IVA were performed at diagnosis. For MSP type VI, mutation analysis of ARBS gene and for MPS type IVA, GALNS gene.

The median age at diagnosis was 15 years $(\mathrm{SD}=16 ; \mathrm{min}=5$; $\max =52, n=14 / 14)$. When patients of both types of MPS were evaluated separately, patients with MPS VI present at a median age (in years) of $29(\mathrm{SD}=14.96 ; \min =5 ; \max =45 ; \mathrm{n}=9 / 9)$ and patients with MPS IVA had a median age of 11years $(\mathrm{SD}=18.38$; $\min =10 ; \max =52 ; \mathrm{n}=5 / 5)$.

The median activity of arylsulfatase B was $9 \mu \mathrm{g} / \mathrm{h} / \mathrm{mg}$ protein $(\mathrm{SD}=30, \min =2.1 ; \max =97 ; \mathrm{n}=9 / 9$; normal range: $72-176 \mu \mathrm{g} / \mathrm{h} /$ $\mathrm{mg}$ protein) in MPS VI patients and the median activity of $\mathrm{N}$-acetylgalactosamine-6-sulfatase was $2.95 \mu \mathrm{mol} / \mathrm{l} / 20 \mathrm{~h}$ $(\mathrm{SD}=3.19 ; \min =0 ; \max =97 ; \mathrm{n}=5 / 5$; normal range: $>8 \mu \mathrm{mol} /$ $1 / 20 h)$. Patients with MPS VI displayed median urinary GAG of $82.9 \mu \mathrm{g} / \mathrm{mg} / \mathrm{mg}$ creatinine $(\mathrm{SD}=45.19 ; \min =44 ; \max =180$; $\mathrm{n}=8 / 9$; normal range: $72-175 \mu \mathrm{g} / \mathrm{g} / \mathrm{mg}$ creatinine). For MPS IVA, we could retrieve data from a unique patient $(55.73 \mu \mathrm{g} / \mathrm{g} / \mathrm{mg}$ creatinine). Patients 4 and 5 were siblings and carry the same mutation (p.Tyr210Cys). Both presented with arylsulfatase B activity below the normal range.

Table 2 summarizes the anthropometric data and the findings regarding the first clinical manifestation as well as the cardiac and ophthalmological follow-up outcomes found in the medical records of the enrolled population. All patients had osteoarticular problems as the first clinical manifestation. Ten cases (71.4\%) were initially considered to have any kind of hip dysplasia or pain, or femoral head avascular necrosis; three were diagnosed as presenting gait abnormalities (21.4\%). After hip radiographic evaluation, all patients were considered to present Perthes-like disease.

The median height in the studied population was 145 $\mathrm{cm}(\mathrm{SD}=11.86 ; \min =120 ; \max =166, \mathrm{n}=13 / 14)$. When the subpopulations were analyzed, patients with MPS VI had a median height of $145 \mathrm{~cm}(\mathrm{SD}=8.11 ; \min =131 ; \max =152 ; \mathrm{n}=8 / 9)$ similarly to patients with MPS IVA $(S D=17.52 ; \min =120$; $\max =166 ; n=5 / 5)$. Concerning body weight, the median of all patients was $47 \mathrm{~kg}(\mathrm{SD}=10.84 ; \min =31 ; \max =66 ; \mathrm{n}=13 / 14)$. Patients with MPS VI showed a median weight of $51 \mathrm{~kg}$ $(\mathrm{SD}=11.41 ; \min =31 ; \max =66 ; \mathrm{n}=8 / 9)$ and patients with MPS IVA had a median of $39 \mathrm{~kg}(\mathrm{SD}=8.35 ; \min =35 ; \max =56 ; \mathrm{n}=5 / 5)$. Body weight and height $\mathrm{z}$-scores are detailed in the Table 2. 
Table 2 - Outcomes of anthropometric, cardiac and ophthalmological finding in the study cohort

\begin{tabular}{|c|c|c|c|c|c|c|c|c|}
\hline Patient & $\begin{array}{l}\text { Height } \\
\text { (cm) }\end{array}$ & $\begin{array}{l}\text { Height } \\
\text { z-score }\end{array}$ & $\begin{array}{l}\text { Weight } \\
\text { (kg) }\end{array}$ & $\begin{array}{l}\text { Weight } \\
\text { z-score }\end{array}$ & $\begin{array}{l}\text { First clinical } \\
\text { manifestation }\end{array}$ & Cardiac findings & $\begin{array}{l}\text { Ophthalmological } \\
\text { findings }\end{array}$ & $\begin{array}{c}\text { Age at ERT } \\
\text { initiation (years) }\end{array}$ \\
\hline 1 & 134 & -0.6 & 31 & -0.34 & $\begin{array}{l}\text { Gait disturbance } \\
\text { and femoral head } \\
\text { avascular necrosis }\end{array}$ & Mild aortic stenosis & $\begin{array}{l}\text { Hypermetropia and } \\
\text { very mild corneal } \\
\text { clouding }\end{array}$ & 16 \\
\hline 2 & 145 & -2.8 & 47 & -1.52 & $\begin{array}{l}\text { Claw hands and } \\
\text { corneal clouding }\end{array}$ & $\begin{array}{l}\text { Thickening of mitral, } \\
\text { aortic and tricuspid valves }\end{array}$ & $\begin{array}{l}\text { Glaucoma, corneal } \\
\text { transplantation }\end{array}$ & $?$ \\
\hline 3 & 132 & -6.1 & 39 & -4.89 & Hip pain & $\begin{array}{l}\text { Thickening of mitral, } \\
\text { aortic and tricuspid } \\
\text { valves; altered ventricular } \\
\text { relaxation }\end{array}$ & $\begin{array}{l}\text { Glaucoma, corneal } \\
\text { transplantation }\end{array}$ & 35 \\
\hline 4 & 149 & -3.8 & 58 & -1.33 & $\begin{array}{l}\text { Hip pain and } \\
\text { affected older } \\
\text { sibling }\end{array}$ & $\begin{array}{c}\text { Thickening of mitral } \\
\text { and aortic valves; mitral } \\
\text { valve stenosis; left atrium } \\
\text { hypertrophy }\end{array}$ & Not specified & 31 \\
\hline 6 & 131 & 4.8 & 59 & 5.29 & $\begin{array}{l}\text { Joint pain and } \\
\text { bone dysplasia }\end{array}$ & Normal & $\begin{array}{l}\text { Bilateral cornea } \\
\text { transplantation }\end{array}$ & $?$ \\
\hline 7 & 145 & 1.8 & 48 & 2.23 & Hip dysplasia & $?$ & Mild corneal clouding & 26 \\
\hline 8 & $?$ & $?$ & $?$ & $?$ & $\begin{array}{l}\text { Hip dysplasia and } \\
\text { valvulopathy }\end{array}$ & $\begin{array}{l}\text { Mitral and aortic } \\
\text { valves thickness and } \\
\text { regurgitation, ventricle } \\
\text { diastolic dysfunction of } \\
\text { grade I }\end{array}$ & $\begin{array}{l}\text { Severe corneal } \\
\text { clouding }\end{array}$ & 46 \\
\hline 9 & & -2.9 & & -0.25 & Short stature & & & \\
\hline 11 & 146 & -1.3 & 42 & -0.46 & Hip dysplasia & Normal & Not performed & Not initiated \\
\hline 12 & 130 & -5.1 & 37 & -3.91 & Bone dysplasia & $\begin{array}{l}\text { Mild tricuspid and mitral } \\
\text { valve insufficiency; } \\
\text { prolonged biventricular } \\
\text { relaxation }\end{array}$ & Astigmatism & 54 \\
\hline 13 & 120 & -2.8 & 35 & 0.28 & Gait disturbance & $\begin{array}{l}\text { Mild tricuspid valve } \\
\text { insufficiency }\end{array}$ & Mild corneal clouding & Not initiated \\
\hline 14 & 145 & 0.9 & 39 & 0.97 & Hip pain & Normal & Normal & 13 \\
\hline
\end{tabular}

?: not known. Patients 4 and 5 are siblings. All of the detailed findings are based on the most recent annotation on the medical records of the enrolled patients. CDC Height for Age and Weight for Age growth charts were used to calculate the z-scores.

Seven patients with MPS VI presented valvulopathy, one had no data and one had no cardiac involvement alterations. As for MSP IVA patients, three patients (out of five) had cardiac involvement by the time of the data collection.

Ophthalmological problems were found in most of the patients independently of MPS type $(n=9 / 14)$. Four patients had corneal clouding; three had already been subjected to corneal transplantation due to corneal clouding or glaucoma; two patients had glaucoma and one patient had astigmatism or hypermetropia. Five patients had no data (one of them did not have an ophthalmological exam recorded).

The median age at ERT initiation for all patients was 26 years $(\mathrm{SD}=14.02 ; \min =15 ; \max =54, \mathrm{n}=9 / 14)$. When patients of both types of MPS were evaluated separately, patients with MPS VI started ERT at a median age of 28.5 years $(\mathrm{SD}=11.02$; $\mathrm{min}=16$; 
$\max =46 ; n=6 / 9)$ and patients with MPS IVA started ERT at a median age of 17 years $(S D=21.96 ; \min =15 ; \max =54 ; n=3 / 5)$.

Table 3 illustrates the findings regarding orthopedic involvement of enrolled patients with MPS VI and IVA. For
MPS VI patients, spinal cord compression, lordosis and increased density and irregularity of femur heads were the most frequent findings (Figure 1). All patients with MPS IVA $(n=5 / 5)$ presented with irregularity of their femoral heads (Figures 2, 3 and 4).

Table 3 - Outcomes of orthopaedic imaging in the study cohort

\begin{tabular}{|c|c|c|}
\hline Patient & Spine & Hips \\
\hline 1 & Narrow cervical canal without spinal compression & Bilateral dysplasia and subluxation of the lateral and superior femoral heads \\
\hline 2 & Cervical lordosis & Not specified \\
\hline 3 & Spinal cord compression & Increased density and irregularity of femur heads \\
\hline 4 & Spinal cord compression, lordosis & Not specified \\
\hline 5 & $\begin{array}{c}\text { Cervical myelopathy, disc protrusion and spinal stenosis; } \\
\text { narrow cervical canal, platispondilia }\end{array}$ & Bilateral displacement of hip \\
\hline 6 & Oval thoracic and lumbar vertebral bodies & Not specified \\
\hline 7 & Spinal cord compression & Bilateral hip dysplasia \\
\hline 8 & Lumbosacral lordosis & Hip dysplasia \\
\hline 9 & Platispondilia in thoracic and lumbar vertebrae & Not specified \\
\hline 10 & Lumbar hyperlordosis and spinal cord compression & Increased density and irregularity of femur heads \\
\hline 11 & Thoracic scoliosis & Irregular femoral heads \\
\hline 12 & Narrow cervical canal associated with mild syringomyelia & Bilateral displacement of hip \\
\hline 13 & Not specified & Bilateral displacement of hip \\
\hline 14 & Spondyloepiphyseal dysplasia & Bilateral hip dysplasia \\
\hline
\end{tabular}

Patients 4 and 5 are siblings. All of the detailed findings are based on the most recent annotation on the medical records of the enrolled patients. Results from X-ray and magnetic resonance imaging studies.

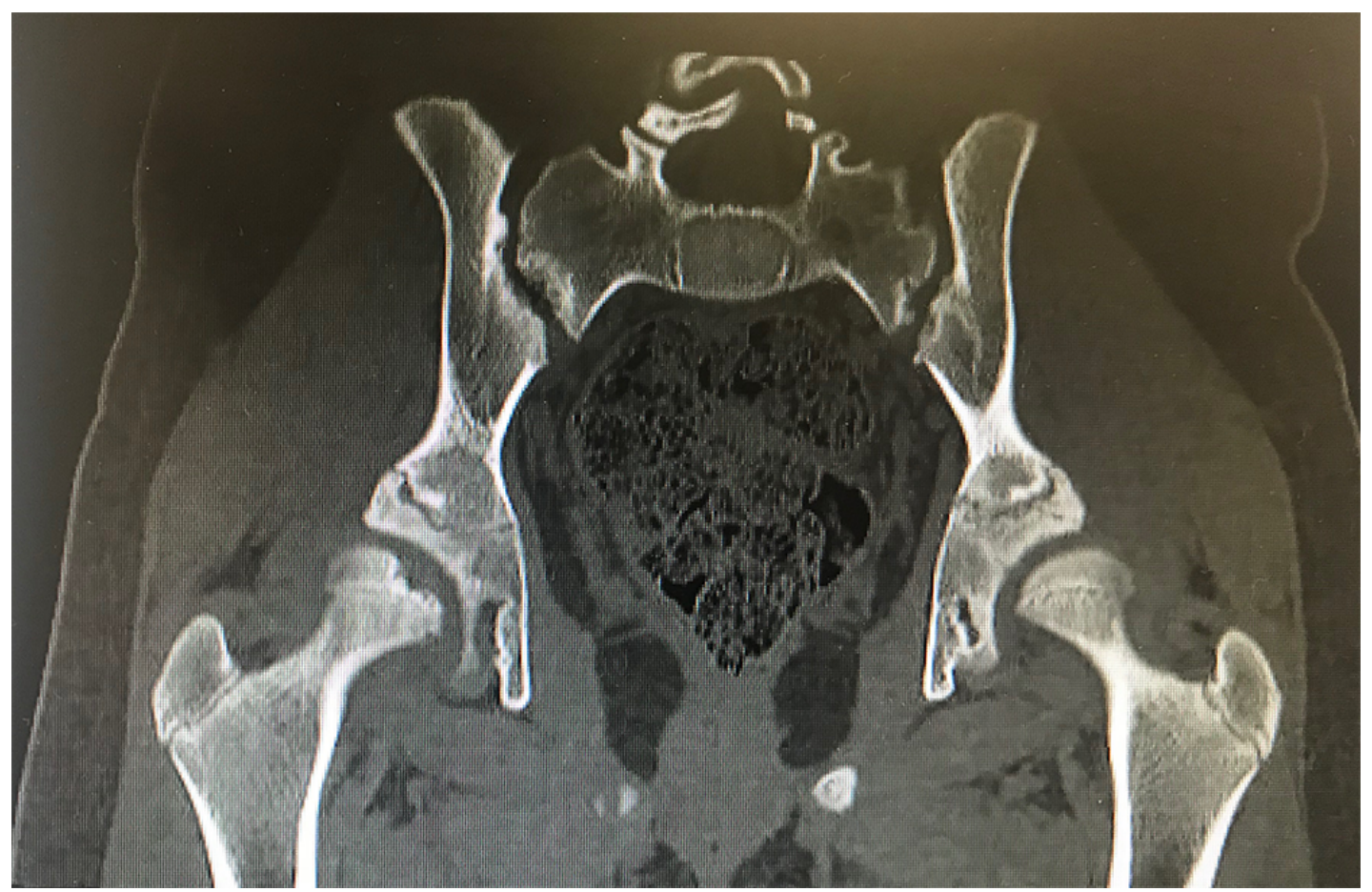

Figure 1. Computed tomography of hip from a female 16-year-old MPS VI patient (patient \#1) with gait disturbance and pain showing hip dysplasia characterized by shallow and irregular acetabulum, triradiate cartilage enlargement and deficiency in the development of the acetabular superior rim. 
(A)

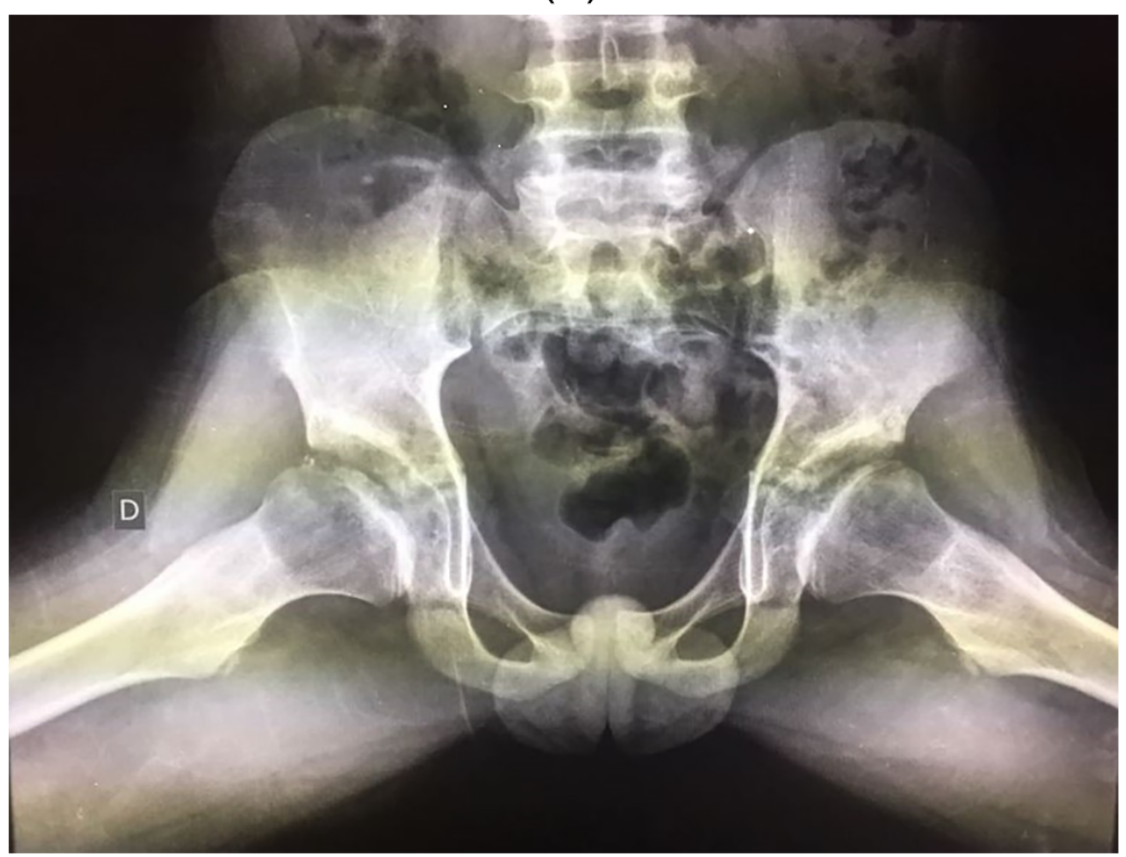

(B)

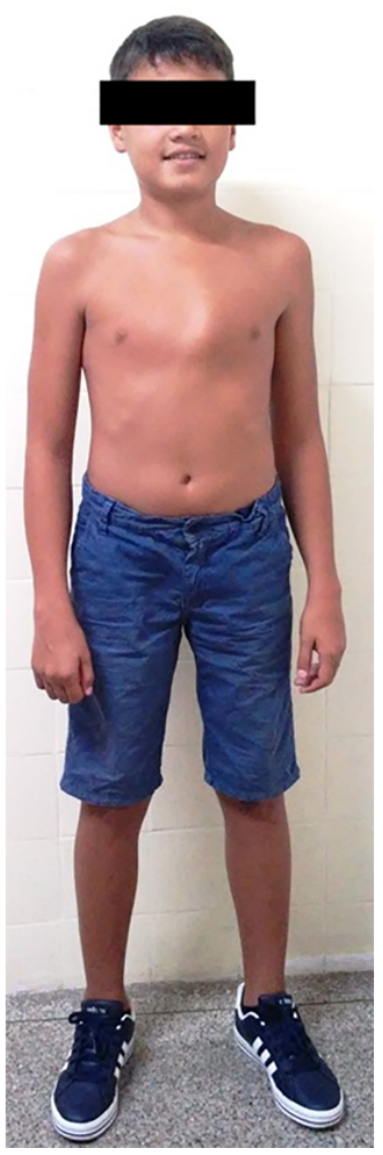

Figure 2. (A) Hip radiography of a male 14-year-old MPS IVA patient (patient \#9) showing shallow acetabular cavities, irregular bilaterally contours, widening of the joint space, reduction of $\mathrm{V}$-shaped with increased density and irregularity of the contours of the femoral heads bilaterally and flattened in the loading zones; (B) Pectus carinatum in the same patient. 
(A)



(B)
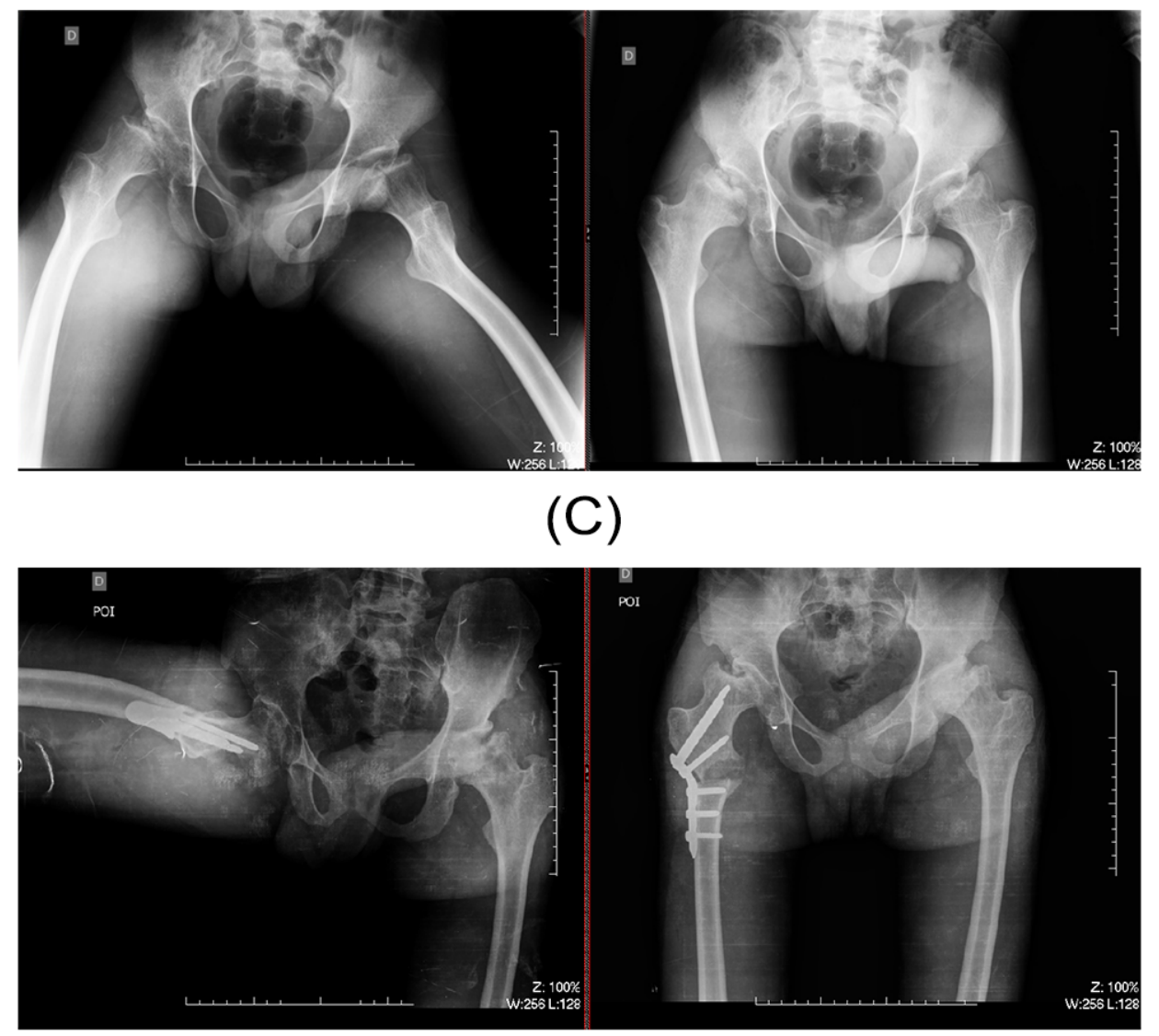

Figure 3. (A) Radiography of hip from a male 9-year-old MPS IVA patient (\#patient 10) with acetabular dysplasia, lateral displacement (subluxation) of the femoral head associated with flattening and fragmentation, resembling femoral head avascular necrosis or Perthes disease); (B) Hip radiography of the same patient at the age of 17 years showing acetabular dysplasia, lateral displacement (subluxation) of the femoral head associated with flattening and fragmentation - resembling femoral head avascular necrosis or Perthes disease) and (C) Post-operative (right valgus osteotomy) hip radiography of the same patient. 


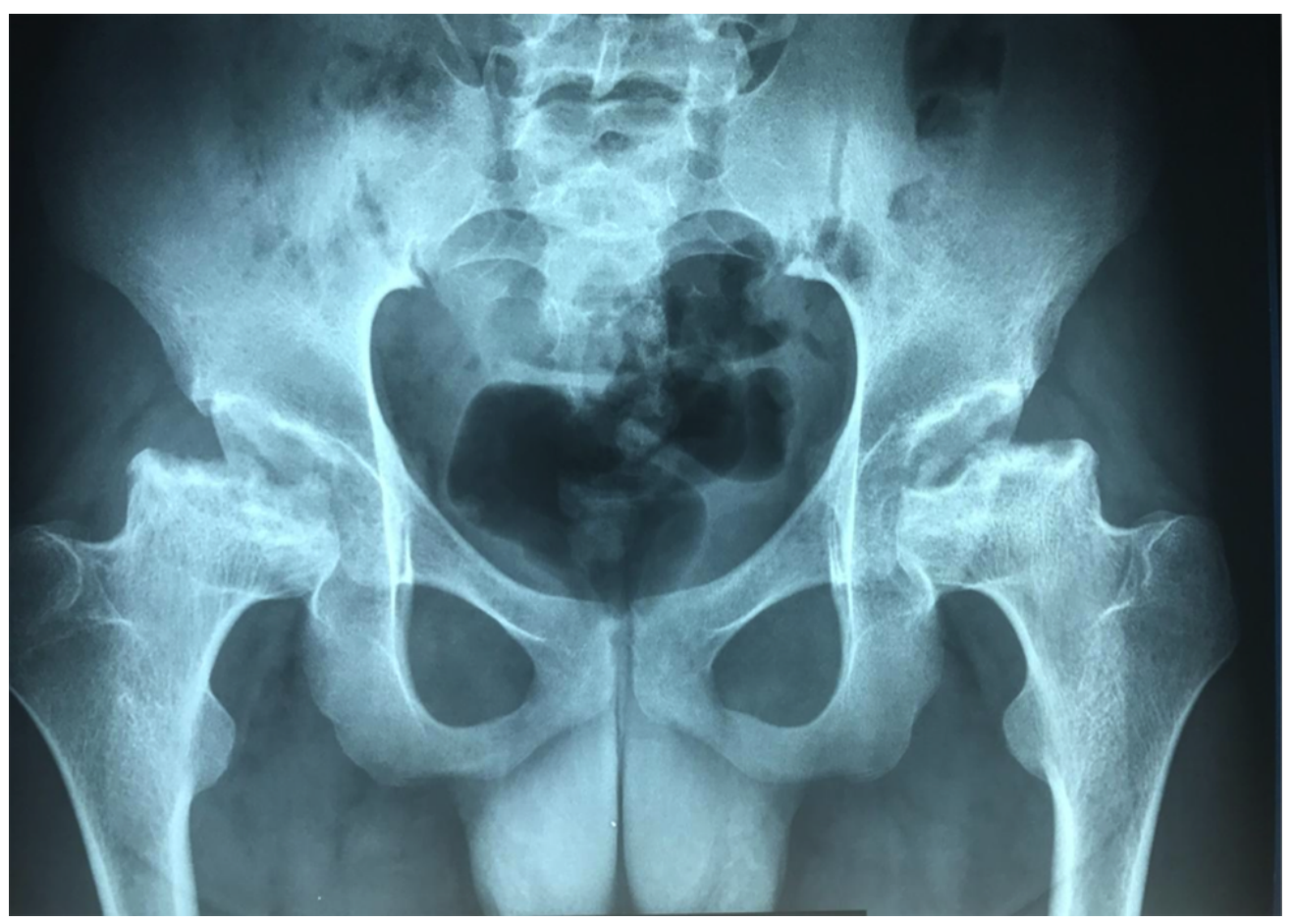

Figure 4. Hip radiography of a male 15-year-old MPS IVA patient (\#patient 14) with acetabular dysplasia, subluxation of the femoral head associated with flattening and fragmentation, resembling femoral head avascular necrosis or Perthes disease.

\section{Discussion}

All patients presented with osteoarticular problems as the first clinical manifestation irrespective of MPS type, which worsened over time in association with cardiac and ophthalmology issues. Radiographic analysis of the hip demonstrated that all patients had findings resembling bilateral Perthes-like disease. These statements are in line with the fact that orthopedists and rheumatologists are among the most-sought specialists by patients with non-classical phenotypes before receiving a correct diagnosis, due to the osteoarticular problems complaints. MPS is underdiagnosed not only because of the extensive heterogeneity of the disease and rarity of these disorders but also due to the lack of awareness of healthcare professionals, limited access to screening and diagnostic methods [13]. Therefore, the current study emphasizes the possible misdiagnosis between Perthes disease and non-classical MPS, the so-called Perthes-like disease.

In our population, MPS presentation (for both VI and IVA) involved the osteoarticular system, leading to joint pain, gait disturbance, hip dysplasia and even the diagnosis of femoral head avascular necrosis. These findings are in agreement with those reported by Tummolo et al. [9], who also concluded that the first clinical features are limited to minor skeletal abnormalities and hip pain. Such progressive orthopedic involvements may lead to a subsequent arthritis, restricted range of motion and pain that together may hamper the ability to walk and to perform daily activities, affecting the health-related quality of life of these patients [15].
There is a health-worsening disease course over time, regardless of the phenotype of the disease [8]. Within this context, the follow-up orthopedic outcomes revealed that skeletal deformities became more evident, such as spinal cord compression, lordosis, alteration of vertebral bodies and disc protrusion. In some cases, patients underwent surgical intervention, such as replacement of hip joint and spinal cord decompression. Collectively, these findings reinforce the urgency to raise awareness among orthopedists, rheumatologists and related specialists. Unfortunately, radiographic findings from undiagnosed patients may constitute an important confounder because of their similarities with findings from other disorders, such as some forms of spondyloepiphyseal dysplasia and bilateral Perthes-like disease [6].

In this study, correct diagnosis were established at a median age of 29 years in patients with MPS VI and at a median age of 11 years in patients with MPS IVA. It has been described that patients with MPS VI may develop symptoms within the first year of life, as verified by Jurecka et al. [16]. These authors had studied a cohort of 49 patients from eight international centers in which 33\% of these patients had an attenuated phenotype of MPS IVA. Concerning MPS IVA, the International Morquio A Registry $(n=326)$ reported that the mean age at diagnosis was 4.7 years of age [17]. Thus, our findings are in accordance with the concept that patients with non-classical phenotypes are commonly diagnosed at a later age.

At first suspicion of MPS, quantitative analysis of total urinary GAG is routinely performed as the initial step of laboratory testing [18]. Patients with non-classical MPS may 
have urinary GAG levels within the normal range and have a height measurement that is above $140 \mathrm{~cm}$, thus hampering the diagnosis [2]. In our population, patients with MPS VI presented with urinary GAG within the normal range, while the urinary GAG levels from our patient with MPS IVA were below normal range. Other case series reported that urinary GAG levels can have fluctuating results throughout life in this phenotype presentation $[7,10]$.

As discussed by Guffon and colleagues [19], the adult height attained depends on phenotype severity, and patients with nonclassical phenotypes usually are taller than $140 \mathrm{~cm}$. We found that the median height of this patient group was $145 \mathrm{~cm}$ (for both MPS types). These results reinforce the assumption that growth impairment in patients with osteoarticular disturbance should raise suspicions of possible non-classical MPS disorders.

Even though patients suspected to have an MPS disorder and presenting with the quantitative urinary GAG within the normal range, some authors have argued that non-classical forms of MPS cannot be discarded without the investigation of lysosomal enzymes activity or genetic studies in patients with pronounced osteoarticular manifestations $[2,3,6,20]$. In light of such a large percentage of patients experiencing delays in accurate diagnosis or misdiagnosed, some authors have proposed algorithms with presenting manifestations and possible diagnosis both for patients with MPS VI and IVA $[7,16]$. In our study, patients with MPS VI showed a decreased activity of arylsulfatase B while patients with MPS IVA showed a decrease in $\mathrm{N}$-acetylgalctosamine-6-sulfatse activity, thus, confirming MPS diseases. It has been discussed that in patients with the non-classical form of MPS VI, the evaluation of a second sulfatase should be promptly performed to rule out multiple sulfatase deficiency, a disease without specific treatment at this time [4].

Follow-up outcomes also revealed that all patients had potentially life-threatening cardiac manifestations. More specifically, the majority of enrolled patients presented with valvulopathy (i.e., mitral, aortic and tricuspid thickened valves). Other cardiac abnormalities such as altered ventricular relaxation and left atrium hypertrophy were also found. It is well-established that cardiac compromises, particularly valve diseases, are virtually found in all patients with MPS VI [21]. Interestingly, dermatan sulphate is the most predominant GAG found in cardiac valve connective tissues and blood vessels. Thus, this GAG accumulation can progressively promote thickening and deformation of valves [22,23].

Similarly, many patients presented with corneal clouding and glaucoma. Three patients had underwent corneal transplantation. In fact, corneal clouding and glaucoma are commonly reported in patients with MPS due to GAG accumulation, which lead to disruption of collagen fibrils in stroma and increase intraocular pressure in the anterior segments of the eye [24].

More than half $(64.3 \%, n=9 / 14)$ of the patients enrolled in this study was receiving enzyme replacement therapy (ERT). This treatment has been effective in improving endurance and pulmonary function in patients, with limited positive effects on cardiac abnormalities, and with almost no-effect on ocular involvement [25]. Unfortunately, to date, while the vast majority of physicians infrequently include MPS as a potential diagnosis for patients with osteoarticular abnormalities without inflammation, early administration of ERT is essential to maximize the beneficial effects of this treatment $[2,25]$.

Our findings underscore that it is critical to consider non-classical MPS VI and IV as diagnoses for patients who report osteoarticular abnormalities overlapping clinical bilateral Perthes disease in absence of inflammatory findings; in addition, isolated Perthes-like disease in the radiographic exam should also raise the suspicion of non-classical MPS. The results obtained demonstrate that all enrolled patients with non-classical phenotypes of MPS displayed orthopedic involvement that worsened over time followed by cardiac and ophthalmological abnormalities. Although these patients may be particularly difficult to diagnose, our findings may provide awareness for orthopedists and other specialists thus stressing the great heterogeneity of non-classical phenotypes observed in MPS may help to shorten the time needed to diagnosis.

\section{Acknowledgments}

The authors would like to thank Daniela Giovannetti, MD, Elaina Jurecki, MS, RD and Debora Mesojedovas, PharmD for contributions and BioMarin Brasil Farmacêutica Ltda., which sponsored the preparation of this article and reviewed the article for medical and scientific accuracy. A special thanks to Rede MPS Brasil for the genetic and enzymatic diagnosis support. Camilla Patti Hissamura provided the medical writing of this manuscript.

\section{Funding}

The writing of the manuscript was supported by BioMarin Brasil Farmacêutica Ltda., but authors are entirely responsible for the scientific content of the manuscript.

\section{Authors' Contributions}

All authors were responsible for the study concept and design, assisted data acquisition, analysis and interpretation. The manuscript was written by a medical writer, but all authors provided critical revision of the manuscript for important intellectual content.

\section{Conflicts of Interest}

CFMS has received honoraria for presentations from Shire and BioMarin and received advisory board honoraria from BioMarin; ACS has received honoraria from BioMarin; NSA has received honoraria for presentation from BioMarin; $\mathrm{CPOP}$ has receives honoraria from BioMarin; DDGH has received educational travel grants and/or speaker honoraria from BioMarin, Shire, Sanofi-Genzyme and Ultragenyx; JP has received advisory 
board honoraria from BioMarin; CML has received honoraria for speakers' fees from Actelion, Genzyme, Biomarin, PTC and Shire HGT; all fees are donated to the CML Medical Foundation for Research and Genetic Diagnosis Support for families with unknown genetic disorders; MAM has received honoraria for lectures from BioMarin, Shire, Sanofi-Genzyme; TSPCM is employee of BioMarin Brasil Farmacêutica Ltda. For the remaining authors none were declared.

\section{References}

1. Yano S, Moseley K, Pavlova Z. Postmortem studies on a patient with mucopolysaccharidosis type I: histopathological findings after one year of enzyme replacement therapy. $J$ Inherit Metab Dis. 2009;32:s53-s57. doi:10.1007/s10545009-1057-4

2. Harmatz P, Shediac R. Mucopolysaccharidosis VI: pathophysiology, diagnosis and treatment. Front Biosci. 2017;22:385-406. doi:10.2741/4490

3. Lachman RS, Burton BK, Clarke LA, et al. Mucopolysaccharidosis IVA (Morquio A syndrome) and VI (Maroteaux-Lamy syndrome): under-recognized and challenging to diagnose. Skeletal Radiol. 2014;43:359-69. doi:10.1007/s00256-013-1797-y

4. Pinto E Vairo F, Conboy E, de Souza CFM, et al. Diagnosis of attenuated Mucopolysaccharidosis VI: clinical, biochemical, and genetic pitfalls. Pediatrics. 2018;142(6):e20180658. doi:10.1542/peds.2018-0658

5. Hendriksz C. Improved diagnostic procedures in attenuated mucopolysaccharidosis. Br J Hosp Med (Lond). 2011;72: 91-5. doi:10.12968/hmed.2011.72.2.91

6. Hecht JT, Scott CI Jr, Smith TK, et al. Mild manifestations of the Morquio syndrome. Am J Med Genet. 1984;18:369371. doi:10.1002/ajmg.1320180222

7. Thümler A, Miebach E, Lampe C, et al. Clinical characteristics of adults with slowly progressing mucopolysaccharidosis VI: a case series. J Inherit Metab Dis. 2012;35:1071-1079. doi:10.1007/s10545-012-9474-1

8. Peracha $\mathrm{H}$, Sawamoto $\mathrm{K}$, Averill L, et al. Molecular genetics and metabolism, special edition: Diagnosis, diagnosis and prognosis of Mucopolysaccharidosis IVA. Mol Genet Metab. 2018;125:18-37. doi:10.1016/j.ymgme.2018.05.004

9. Tummolo A, Gabrielli O, Gaeta A, et al. Bisphosphonate treatment in a patient affected by MPS IVA with osteoporotic phenotype. Case Rep Med. 2013: 891596. doi:10.1155/2013/891596

10. Scarpa M, Buffone E, Marca PL, et al. Difficulties in diagnosing slowly progressive mucopolysaccharidosis VI: A case series. J Pediatr Rehabil Med. 2010;3:71-75. doi:10.3233/prm-2010-0104

11. Fang-Kircher SG, Böck A, Fertschak W, et al. Morquio disease in a patient diagnosed as having Perthes disease for
38 years. J Inherit Metab Dis. 1995; 18(1):94-95. doi:10.1007/ bf00711389

12. Cimaz R, Coppa GV, Koné-Paut I, et al. Joint contractures in the absence of inflammation may indicate mucopolysaccharidosis. Pediatr Rheumatol Online. 2009;7:18. doi:10.1186/1546-0096-7-18

13. Rocha Siqueira TC, de Souza CF, Lompa P, et al. Screening for attenuated forms of mucopolysaccharidoses in patients with osteoarticular problems of unknown etiology. JIMD Rep. 2016;26:99-102. doi:10.1007/8904_2015_484

14. Mendelsohn NJ, Wood T, Olson RA, et al. Spondyloepiphyseal dysplasias and bilateral Legg-Calvé-Perthes disease: diagnostic considerations for mucopolysaccharidoses. JIMD Rep. 2013;11:125-32. doi:10.1007/8904_2013_231

15. Giugliani R, Fainboim A, Kim CA, et al. Recommendations for assessment and management of health-related quality of life in patients with mucopolysaccharidoses in Latin America. J Inborn Errors of Metab \& Screening. 2019;7:e20190004. doi:10.1590/2326-4594-jiems-2019-0004

16. Jurecka A, Zakharova E, Cimbalistiene L, et al. Mucopolysaccharidosis type VI in Russia, Kazakhstan, and Central and Eastern Europe. Pediatr Int. 2014;56:520-5. doi:10.1111/ped.12281

17. Montaño AM, Tomatsu S, Gottesman GS, et al. International Morquio A Registry: clinical manifestation and natural course of Morquio A disease. J Inherit Metab Dis. 2007;30(2):165-174. doi:10.1007/s10545-007-0529-7

18. Bhattacharya K, Balasubramaniam S, Choy YS, et al. Overcoming the barriers to diagnosis of Morquio A syndrome. Orphanet J Rare Dis. 2014;9:192. doi:10.1186/ s13023-014-0192-7

19. Guffon N, Journeau P, Brassier A, et al. Growth impairment and limited range of joint motion in children should raise suspicion of an attenuated form of mucopolysaccharidosis: expert opinion. Eur J Pediatr. 2019;178:593-603. doi:10.1007/s00431-019-03330-X

20. Litjens T, Brooks DA, Peters C, et al. Identification, expression, and biochemical characterization of $\mathrm{N}$-acetylgalactosamine-4-sulfatase mutations and relationship with clinical phenotype in MPS-VI patients. Am J Hum Genet. 1996;58(6):1127-1134. https://www.ncbi. nlm.nih.gov/pmc/articles/pmc1915068/

21. Fesslová V, Corti P, Sersale G., et al. The natural course and the impact of therapies of cardiac involvement in the mucopolysaccharidoses. Cardiol Young. 2009;19(2):170178. doi:10.1017/S1047951109003576

22. Brands M, Roelants J, de Krijger R, et al. Macrophage involvement in mitral valve pathology in mucopoly saccharidosis type VI (Maroteaux-Lamy syndrome). Am J Med Genet A. 2013;161A:2550-253. doi:10.1002/ ajmg.a.36105 
23. Golda A, Jurecka A, Tylki-Szymanska A. Cardiovascular manifestations of mucopolysaccharidosis type VI (Maroteaux-Lamy syndrome). Int J Cardiol. 2012;158(1):611. doi:10.1016/j.ijcard.2011.06.097

24. Ashworth JL, Biswas S, Wraith E, et al. Mucopolysaccharidoses and the eye. Surv Ophthalmol. 2006;51(1):117. doi:10.1016/j.survophthal.2005.11.007
25. Harmatz P, Giugliani R, Schwartz I, et al. Enzyme replacement therapy for mucopolysaccharidosis VI: A Phase 3, randomised, double-blind, placebocontrolled, multinational study of recombinant human $\mathrm{N}$-acetylgalactosamine 4-sulfatase and follow-on, openlabel extension study. J Pediatr. 2006;148:533-539. doi:10.1016/j.jpeds.2005.12.014 